\title{
BMJ Open Prevalence of alcohol and drug use in injured British Columbia drivers
}

\author{
Jeffrey R Brubacher, ${ }^{1}$ Herbert Chan, ${ }^{1}$ Walter Martz, ${ }^{2}$ William Schreiber, ${ }^{2,3}$ \\ Mark Asbridge, ${ }^{4}$ Jeffrey Eppler, ${ }^{1}$ Adam Lund, ${ }^{1}$ Scott Macdonald, ${ }^{5}$ Olaf Drummer, ${ }^{6}$ \\ Roy Purssell, ${ }^{1,7}$ Gary Andolfatto, ${ }^{1}$ Robert Mann, ${ }^{7}$ Rollin Brant ${ }^{8}$
}

To cite: Brubacher JR, Chan H, Martz W, et al. Prevalence of alcohol and drug use in injured British Columbia drivers. BMJ Open 2016:6:e009278.

doi:10.1136/bmjopen-2015009278

- Prepublication history for this paper is available online. To view these files please visit the journal online (http://dx.doi.org/10.1136/ bmjopen-2015-009278).

Received 1 July 2015 Revised 4 December 2015 Accepted 4 December 2015

CrossMark

For numbered affiliations see end of article.

Correspondence to Dr Jeffrey R Brubacher; jbrubacher@shaw.ca

\section{ABSTRACT}

Objectives: Determine the prevalence of drug use in injured drivers and identify associated demographic factors and crash characteristics.

Design: Prospective cross-sectional study.

Setting: Seven trauma centres in British Columbia, Canada (2010-2012).

Participants: Automobile drivers who had blood obtained within $6 \mathrm{~h}$ of a crash.

Main outcome measures: We analysed blood for cannabis, alcohol and other impairing drugs using liquid chromatography/mass spectrometry (LCMS).

Results: 1097 drivers met inclusion criteria. 60\% were aged $20-50$ years, $63.2 \%$ were male and $29.0 \%$ were admitted to hospital. We found alcohol in $17.8 \%$ (15.6\% to $20.1 \%$ ) of drivers. Cannabis was the second most common recreational drug: cannabis metabolites were present in $12.6 \%$ (10.7\% to $14.7 \%$ ) of drivers and we detected $\Delta$-9-tetrahydrocannabinol ( $\Delta$-9-THC) in $7.3 \%(5.9 \%$ to $9.0 \%)$, indicating recent use. Males and drivers aged under 30 years were most likely to use cannabis. We detected cocaine in $2.8 \%(2.0 \%$ to $4.0 \%)$ of drivers and amphetamines in $1.2 \%(0.7 \%$ to $2.0 \%)$. We also found medications including benzodiazepines $(4.0 \%(2.9 \%$ to $5.3 \%))$, antidepressants $(6.5 \%(5.2 \%$ to $8.1 \%))$ and diphenhydramine $(4.7 \%(3.5 \%$ to $6.2 \%))$. Drivers aged over 50 years and those requiring hospital admission were most likely to have used medications. Overall, $40.1 \%(37.2 \%$ to $43.0 \%)$ of drivers tested positive for alcohol or at least one impairing drug and $12.7 \%$ $(10.7 \%$ to $14.7 \%)$ tested positive for more than one substance.

Conclusions: Alcohol, cannabis and a broad range of other impairing drugs are commonly detected in injured drivers. Alcohol is well known to cause crashes, but further research is needed to determine the impact of other drug use, including drug-alcohol and drug-drug combinations, on crash risk. In particular, more work is needed to understand the role of medications in causing crashes to guide driver education programmes and improve public safety.

\section{BACKGROUND}

Motor vehicle crashes (MVCs) due to impaired driving are a leading cause of
Strengths and limitations of this study

- We analysed blood samples for the presence of active drugs. This allowed us to determine the prevalence of recent drug use in injured drivers. Most previous North American studies were unable to distinguish between drivers with positive metabolites and those with active drug in their blood.

- Rather than reporting the results of drug tests performed for clinical purposes (ie, based on clinical suspicion of drug use), we analysed excess blood that had been obtained for other clinical purposes (ie, not for drug screening). In this way, we avoided the risk of selecting only drivers suspected of using drugs.

- This study had research ethics board approval for waiver of consent because we used excess blood that had been obtained for clinical use and was going to be discarded, and because of the procedures we put in place making it impossible to link toxicology results back to an individual driver. The advantage of this is that we avoid the selection bias that could occur if drivers who used drugs were more likely to refuse to participate.

- First, the excess blood volumes are small which limited analysis in some cases. In particular, we did not always have sufficient blood to perform quantification of drugs (other than cannabinoids). However, the analytic process is sufficient for the purpose of detecting presence versus absence of all drugs.

- Second, we obtained blood from only those drivers who had serious enough injuries that they required blood analysis as part of routine care. This means that drivers with minor injuries were not included and our findings do not apply to drivers with less severe injuries.

preventable injury and death. Alcohol is involved in approximately one-third of serious MVCs resulting in severe injury or death. Many illicit drugs such as cannabis, over-the-counter medications such as antihistamines and prescription medications such as benzodiazepines also impair the psychomotor skills required for safe driving. ${ }^{1-11}$ 
Compared with drunk driving, drug driving remains poorly understood.

Testing drivers for drugs other than alcohol is technically and logistically challenging. Drug testing at the roadside is limited because available portable devices require training in their use and interpretation of results, and these devices detect classes of commonly abused drugs but not the full range of drugs that may affect driving. To get a complete picture, detection and measurement of all the relevant drugs in blood requires analysis by a toxicology lab, which involves time and expense as well as sophisticated instruments operated by highly qualified staff. In addition, unlike alcohol which can be measured easily with a breathalyser, other drugs must be analysed in bodily fluids such as urine, saliva or blood. Urine analysis usually measures inactive metabolites that remain present for days after last use in the case of cocaine and for weeks in heavy cannabis users. Therefore, urine testing identifies drug users but does not provide evidence of impairment or recent drug use. Oral fluid tests can also be used to detect recent drug use but do not yet provide the same diagnostic accuracy as blood testing. ${ }^{12}$

Blood samples provide the best measure of drug concentration levels, but cut-offs to assess whether individuals are impaired have not been agreed upon among scientists. For cannabis, $\Delta$-9-tetrahydrocannabinol ( $\Delta-9$-THC) cut-off levels in whole blood for determining impairment have been suggested by Grotenhermen et $a l,{ }^{13}$ at $6-8 \mathrm{ng} / \mathrm{mL}$ and $2-5 \mathrm{ng} / \mathrm{mL}$ by Hartman and Huestis. ${ }^{14}$ A metabolite (tetrahydrocannabinol carboxylic acid; THC-COOH) is sometimes used to assess past exposure to cannabis, but its presence is unrelated to performance deficits. In most cases, $\Delta-9$-THC $>0$ in whole blood indicates recent use of cannabis (ie, within the previous $4 \mathrm{~h}$ ), although some heavy cannabis users may have positive $\Delta-9$-THC levels that persist for days. ${ }^{15} 16$ Very low blood $\Delta-9$-THC levels (ie, $<2 \mathrm{ng} / \mathrm{mL}$ ) likely have little relationship to driving performance. Drug driving laws vary from country to country. In many countries, including Canada and the Netherlands, drug driving law is based on evidence of impairment and not on per se drug levels. Some jurisdictions, such as Australia, Germany and several states in the USA, have a zero tolerance policy towards driving after using illicit drugs, making it illegal to drive with any detectable level of these drugs in body fluids. Norway is the first country to institute non-zero per se limits for drug driving. ${ }^{17}$

The prevalence of drug driving is most commonly determined in either (1) roadside surveys of drivers selected from the general driving population, (2) in studies of injured drivers after a crash or (3) in coroner's studies of fatally injured drivers. The major limitation of typical roadside surveys is the high refusal rate which is approximately $20 \%$ in recent North American surveys. ${ }^{18}$ Coroners often test fatally injured drivers for alcohol and other drugs, so coroner's data provide an opportunity to estimate the prevalence of drug driving.
Unfortunately, coroner's data may be subject to selection bias if testing is done based on suspicion of drug use rather than routinely in all drivers. In addition, some coroner's services measure and report the presence of inactive metabolites (ie, from urine testing) rather than testing blood samples for the presence of active parent compound. A final limitation of coroner's data is that the prevalence of drug use in fatally injured drivers may differ from that in less severely injured drivers.

Another important population to study is injured drivers treated in hospital. The prevalence of drug use in injured drivers has been studied in several European countries as part of the Driving Under the Influence of Drugs (DRUID) project, ${ }^{19-21}$ as well as in Australia ${ }^{22}$ and Hong Kong. ${ }^{23}$ North American studies of the prevalence of drug use in injured drivers have been conducted in Toronto (1993), ${ }^{24}$ Colorado (2001), ${ }^{25}$ Chicago $(1994)^{26}$ and Baltimore (2005). ${ }^{27} \mathrm{~A}$ recent study from Halifax and Toronto (2014) reported the prevalence of recent alcohol or cannabis use in injured drivers but did not report the prevalence of other drugs. ${ }^{28}$ Most prior North American studies determined drug exposure by measuring the presence of common drug metabolites in urine samples and therefore do not provide accurate estimates of recent drug use. Furthermore, the information is dated. The current study is part of an ongoing project investigating the role of cannabis in MVCs. The aim of the current paper is to determine the prevalence of drug use in injured drivers treated in British Columbia (BC) trauma centres. Secondarily, we report the identity of the drugs that are detected and the demographic characteristics of the drivers with positive drug tests.

\section{Methods}

This study was approved by the University of British Columbia Clinical Research Ethics Board and by the research ethics boards of the Vancouver Coastal Health, Fraser Health, Interior Health, Northern Health and Vancouver Island Health Authority. Permission was granted to waive consent because of the careful procedures developed to protect personal information. In particular, our data handling process ensured that no individual driver could be linked to his/her toxicology results.

Drivers treated in the emergency departments (EDs) at seven participating BC trauma centres between 2010 and 2012 were identified prospectively. All injured automobile drivers who had blood obtained within $6 \mathrm{~h}$ of the crash were eligible. The decision to obtain blood samples was made by the treating physician. In general, blood was obtained when there was a possibility of serious injury based on history (eg, high-speed crash or side impact collision) and/or physical examination (eg, abnormal vital signs or other clinical evidence of potential serious injury). Note that clinicians did not receive the results of drug testing from this study and suspicion of drug use was not a criterion for obtaining blood 
samples. If drug testing was indicated clinically, it would be done on urine samples in the hospital laboratory and not as part of this study. Drivers were excluded if blood samples were not obtained within $6 \mathrm{~h}$ after the crash, no excess blood remained after clinical use or if they were drivers of a motorcycle or commercial vehicle. Drivers were identified using methods that best fit with the workflow at participating hospitals. At the largest hospital, injured drivers are flagged electronically on registration and research assistants identified injured drivers through daily review of an electronic report. Tracking of included and excluded drivers at this site was done using electronic flags. At other centres, charts of injured drivers who had blood testing done were flagged by clinical staff. We were unable to review all ED charts at these sites over the course of the study, but we completed a 1-month comprehensive review of all ED charts at these sites to estimate the numbers of excluded drivers (figure 1).

In all centres, once injured drivers were identified, research assistants reviewed health records (paramedic and ED records) and identified those who had bloodwork obtained within $6 \mathrm{~h}$ of the crash. For these drivers, research assistants went to the hospital laboratory and obtained excess blood if any remained after use for clinical care. This usually occurred between 24 and $48 \mathrm{~h}$

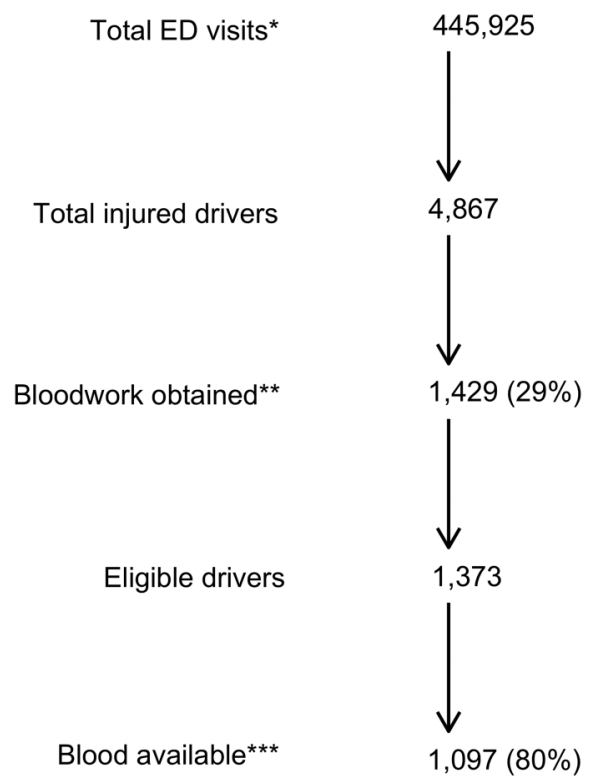

Figure 1 Estimated numbers of drivers over the study period. These numbers are estimated on the basis of a comprehensive chart review of all ED visits at participating sites. *Different sites participated in the study for different lengths of time. The total number of ED visits counts total visits for each site during the times that the site was enrolling patients. ${ }^{*}$ The proportion of drivers who had bloodwork obtained varied by study site from $6 \%$ to $58 \%$. ${ }^{* * *}$ The most common reason for blood being unavailable was that the blood was discarded before research assistants could identify injured drivers and inform the lab. ED, emergency department. from time of blood draw. Blood was relabelled with a study ID replacing patient name, frozen and transported to the British Columbia Provincial Toxicology Centre for later analysis.

In participating hospitals, blood samples from injured drivers are usually analysed for alcohol by enzymatic testing using alcohol dehydrogenase as part of routine trauma care. If alcohol levels were not measured for clinical purposes, they were measured at the Provincial Toxicology Centre using gas chromatography-flame ionization detection with a detection limit of $0.01 \%$ as part of this study. In addition to measuring alcohol, we performed a broad-spectrum drug screen on each patient's blood by liquid chromatography/mass spectrometry (LCMS). The extraction process recovers acidic and basic drugs and is able to detect illicit drugs and their metabolites (cannabinoids, cocaine, amphetamines including designer drugs, opiates) as well as psychotropic pharmaceuticals (including antihistamines, benzodiazepines, other hypnotics and sedating antidepressants). The detection limits was $0.2 \mathrm{ng} / \mathrm{mL}$ for $\Delta-9-\mathrm{THC}$ and $1 \mathrm{ng} /$ $\mathrm{mL}$ for most other substances. When blood tested positive for cannabinoids, we quantified the active ingredient $(\triangle-9-\mathrm{THC})$ and the inactive metabolite (THC-COOH). If enough blood was available, the levels of other drugs that tested positive were quantified. In most cases, samples consisted of whole blood. In a small number of cases $(n=39)$, only plasma specimens were obtained. In this case, plasma results were adjusted to equivalent whole blood results according to international standards. ${ }^{29} 30$

Health records including ambulance records of injured drivers were reviewed and basic demographic and medical information was recorded. We recorded all medications given as part of clinical care, either in ambulance or in the ED, prior to blood draw. These 'post-crash' medications were accounted for when reporting the medications detected in driver blood samples.

For all drugs suspected of impairing driving ability, we report the percentage of drivers who test positive according to age, gender and time of day. We also report the percentage of drivers who had drug levels above the Norwegian legal limit. ${ }^{17}$ We report unadjusted ORs with $95 \%$ CIs and use $\chi^{2}$ tests to compare the prevalence of drug use among drivers of different ages, genders and crash characteristics.

\section{RESULTS}

During the study period, 1097 drivers met study criteria and had blood analysed for drugs. The majority of drivers in our samples were between the ages of 20 and 49 years, and $63.3 \%$ were male. Most $(73.0 \%)$ drivers were brought to hospital by ambulance, $47.5 \%$ required a CT scan and $29 \%$ were admitted to hospital. Blood samples were obtained a median of $87.2 \mathrm{~min}(\mathrm{IQR}=52$ $105 \mathrm{~min}$ ) from the time of crash. Table 1 shows the general characteristics of these injured drivers. 
Table 1 Study population $(n=1097)$ and crash characteristics

\begin{tabular}{lc}
\hline & Number (\%) \\
\hline Male & $704(64)$ \\
Age range (years) & $56(5)$ \\
$<20$ & $259(24)$ \\
$20-29$ & $185(17)$ \\
$30-39$ & $216(20)$ \\
$40-49$ & $183(17)$ \\
$50-59$ & $115(11)$ \\
$60-69$ & $49(5)$ \\
$70-79$ & $34(3)$ \\
$80+$ & $318(29)$ \\
Admitted to hospital & $371(34)$ \\
Blood drawn time from crash $\leq 60$ min & $898(82)$ \\
Blood drawn time from crash $\leq 120$ min & $521(48)$ \\
Required head CT scan & $375(34)$ \\
Single-vehicle crash & $656(60)$ \\
Daytime crash (06:01-18:00) & $441(40)$ \\
Night-time crash (18:01-06:00) & $373(34)$ \\
Weekend crash &
\end{tabular}

\section{Alcohol}

Alcohol was present in $17.8 \%$ of drivers. Most alcoholpositive drivers $(86.7 \%)$ had alcohol concentrations that exceeded the Canadian federal legal limit of $0.08 \%$. Alcohol was detected more often in male $(23.0 \%)$ than in female drivers $(8.4 \%) \quad(\mathrm{OR}=3.26,95 \%$ CI 2.17 to $5.01)$, and in drivers under the age of 30 years (OR=3.64, 95\% CI 2.61 to 5.08). Drivers who required admission to hospital ( $\mathrm{OR}=1.89,95 \%$ CI 1.35 to 2.64) and those involved in night-time crashes $(\mathrm{OR}=12.45$, $95 \%$ CI 8.23 to 18.84$)$ or in single-vehicle crashes $(\mathrm{OR}=6.99,95 \%$ CI 4.91 to 10.06$)$ were also more likely to have used alcohol (table 2).

\section{Cannabis}

The second most common recreational drug, and most common illicit drug, detected was cannabis: $12.6 \%$ of drivers tested positive for cannabis metabolites (THC-COOH), $7.3 \%$ were positive for $\Delta-9-\mathrm{THC}$ and $3.0 \%$ had $\Delta-9-$ THC $>3 \mathrm{ng} / \mathrm{mL}$ (the Norwegian legal limit). $\Delta-9-\mathrm{THC}$ was more often detected in male drivers $(\mathrm{OR}=2.17,95 \%$ CI 1.23 to 4.02$)$, in drivers aged under 30 years $(\mathrm{OR}=2.29,95 \%$ CI 1.40 to 3.72$)$ and in those involved in single-vehicle crashes $(\mathrm{OR}=1.64,95 \%$ CI 1.00 to 2.65). $\Delta-9$-THC was not found significantly more often in drivers admitted to hospital nor in those involved in night-time crashes or weekend crashes. Drivers aged under 30 years were more likely to have $\Delta-9-\mathrm{THC}>3 \mathrm{ng} / \mathrm{mL}(\mathrm{OR}=2.73,95 \%$ CI 1.28 to 5.85$)$, but $\Delta-9-\mathrm{THC}>3 \mathrm{ng} / \mathrm{mL}$ was not found significantly more often in other groups of drivers (table 2).

\section{Other illicit drugs}

Cocaine was positive in $2.8 \%$ of drivers and amphetamines in $1.2 \%$. We found a high prevalence of morphine $(6.0 \%)$ in this sample of injured drivers. After excluding cases where morphine was given prior to blood draw by paramedics $(n=21)$ or in the $\operatorname{ED~}(n=22)$, morphine was detectable in 23 cases $(2.1 \%)$. Our analysis did not allow us to identify which morphine-positive cases, if any, were due to heroin use. Heroin is not detected in blood samples since it is rapidly metabolised to 6-acetylmorphine and then to morphine. Identification of heroin requires analysis of either urine or saliva samples which we did not have access to. ${ }^{12}$ (table 2).

\section{Medications}

Medications including benzodiazepines (4.0\%), zopiclone $(0.6 \%)$, antidepressants $(6.5 \%)$ and opiates including morphine $(4.8 \%)$ were also detected. Benzodiazepines were detected in 55 drivers (5\%), but 13 of these were given benzodiazepines by medical staff prior to blood draw, so benzodiazepines were used by 42 drivers $(4.0 \%)$ prior to the crash. Similarly, the antihistamine diphenhydramine was detected in 121 drivers $(11.0 \%)$, but 75 of these had been given the antinauseant dimenhydrinate by paramedics or hospital staff prior to blood draw. Treatment with dimenhydrinate (diphenhydramine-8-chloro-theophyllinate) will produce a positive test for diphenhydramine, so we excluded these 75 cases. Therefore, 46 drivers $(4.7 \%)$ had used diphenhydramine prior to the crash. In total, $19.9 \%$ of drivers were positive for at least one sedating medication. Drivers aged under 50 years $(\mathrm{OR}=0.67,95 \%$ CI 0.49 to 0.92 ) were less likely to test positive for a medication, and those who were admitted to hospital $(\mathrm{OR}=2.50,95 \%$ CI 1.82 to 3.44$)$ had the highest rate of medication use (table 2).

\section{Poly drug use}

Overall, $40.1 \%$ of drivers tested positive for alcohol or at least one impairing drug and $12.7 \%$ tested positive for more than one substance. The most common combinations of drugs were medications plus recreational drugs $(3.5 \%)$, alcohol plus cannabis (ie, $\Delta-9-\mathrm{THC}$ positive-1.6\%), alcohol plus medications (2.4\%) and alcohol plus recreational drugs (2.3\%) (figure 2). Compared with non-drinking drivers, drivers who had been drinking were more likely to also use other drugs. In particular, cannabis and alcohol were often used together and drivers who tested positive for alcohol were also more likely to test positive for cannabis and vice versa (figure 3 ).

\section{DISCUSSION}

In this population, alcohol was the most commonly detected drug and was present in $17.8 \%$ of drivers. Most alcohol-positive drivers had blood alcohol concentration (BAC) $>0.08 \%$, the Canadian legal limit for driving. Alcohol is well known to impair driving ability and cause collisions. ${ }^{31}$ The risk of collision increases after any 
Table 2 Prevalence of substance use

\begin{tabular}{|c|c|c|c|c|c|c|c|}
\hline \multirow[b]{2}{*}{ Substance } & \multirow[b]{2}{*}{$\begin{array}{l}\text { Prevalence } \\
(95 \% \mathrm{Cl})\end{array}$} & \multicolumn{6}{|l|}{ OR (95\% Cl) } \\
\hline & & Male (vs female) & Age $<30($ vs $>30)$ & $\begin{array}{l}\text { Single vehicle } \\
\text { (vs multivehicle) }\end{array}$ & Night (vs day) & $\begin{array}{l}\text { Weekend } \\
\text { (vs weekday) }\end{array}$ & $\begin{array}{l}\text { Admitted } \\
\text { (vs discharged) }\end{array}$ \\
\hline \multicolumn{8}{|l|}{ Alcohol } \\
\hline BAC $>0.01 \%$ & 17.8 (15.6 to 20.1$)$ & $3.26(2.17$ to 5.01$)$ & 3.64 (2.61 to 5.08$)$ & 6.99 (4.91 to 10.06$)$ & 12.45 (8.23 to 18.84$)$ & 3.97 (2.84 to 5.56 ) & 1.89 (1.35 to 2.64$)$ \\
\hline $\mathrm{BAC}>0.08 \%$ & $15.4(13.4$ to 17.7$)$ & $3.42(2.20$ to 5.49$)$ & 3.77 (2.65 to 5.37$)$ & 6.91 (4.74 to 10.21$)$ & 15.25 (9.46 to 24.58$)$ & 3.89 (2.74 to 5.57$)$ & $1.82(1.28$ to 2.60$)$ \\
\hline \multicolumn{8}{|l|}{ Cannabis } \\
\hline$\Delta-9-\mathrm{THC}>0.2 \mathrm{ng} / \mathrm{mL}$ & 7.3 (5.9 to 9.0$)$ & 2.17 (1.23 to 4.02$)$ & 2.29 (1.40 to 3.70$)$ & 1.64 (1.00 to 2.65$)$ & 0.73 (0.45 to 1.18$)$ & 1.04 (0.62 to 1.72$)$ & $1.43(0.86$ to 2.35$)$ \\
\hline$\Delta-9-\mathrm{THC}>3 \mathrm{ng} / \mathrm{mL}^{*}$ & 3.0 (2.1 to 4.2$)$ & 2.11 (0.88 to 5.82$)$ & $2.73(1.28$ to 5.85$)$ & $0.72(0.29$ to 1.61$)$ & 1.36 (0.62 to 3.14$)$ & 0.84 (0.35 to 1.85 ) & 1.23 (0.53 to 2.69$)$ \\
\hline $\begin{array}{l}\text { THC-COOH } \\
>1 \mathrm{ng} / \mathrm{mL}\end{array}$ & $12.6(10.7$ to 14.7$)$ & 2.19 (1.42 to 3.48$)$ & 2.35 (1.61 to 3.45 ) & 2.13 (1.46 to 3.11$)$ & $0.52(0.36$ to 0.76$)$ & 1.20 (0.81 to 1.75 ) & 1.57 (1.06 to 2.32$)$ \\
\hline \multicolumn{8}{|l|}{ Other drugs } \\
\hline Cocaine $>1 \mathrm{ng} / \mathrm{mL}$ & 2.8 (2.0 to 4.0$)$ & 1.62 (0.69 to 4.24$)$ & 0.72 (0.26 to 1.74$)$ & 2.10 (0.96 to 4.62$)$ & 1.41 (0.64 to 3.07$)$ & 1.85 (0.84 to 4.04$)$ & $2.70(1.23$ to 5.93$)$ \\
\hline Cocaine $>24 \mathrm{ng} / \mathrm{mL}^{*}$ & $1.2(0.7$ to 2.0$)$ & 3.10 (0.67 to 28.94$)$ & $1.10(0.25$ to 3.99$)$ & 2.27 (0.65 to 8.23$)$ & 1.74 (0.50 to 6.33$)$ & 2.28 (0.65 to 8.27 ) & 2.12 (0.58 to 7.43$)$ \\
\hline $\begin{array}{l}\text { Cocaine or } \\
\text { metabolites }\end{array}$ & 7.2 (5.8 to 8.9$)$ & 1.71 (0.99 to 3.04$)$ & 1.48 (0.89 to 2.45$)$ & 2.33 (1.43 to 3.81$)$ & 1.53 (0.94 to 2.50$)$ & 1.42 (0.86 to 2.32$)$ & 2.44 (1.49 to 3.98$)$ \\
\hline $\begin{array}{l}\text { Amphetamine } \\
>1 \mathrm{ng} / \mathrm{mL}\end{array}$ & $1.2(0.7$ to 2.0$)$ & 1.26 & 1.56 & 2.27 (0.65 to & .29 to 28.66 ) & $0.58(0.10$ & $1.09(0.24 t$ \\
\hline $\begin{array}{l}\text { Amphetamine } \\
>41 \mathrm{ng} / \mathrm{mL}^{*}\end{array}$ & 0.6 (0.3 to 1.3$)$ & $1.40(0.23$ to 14.75$)$ & 3.34 (0.56 to 22.90$)$ & $2.58(0.43$ to 17.72$)$ & 3.74 (0.61 to 39.44$)$ & 0.77 (0.07 to 4.74$)$ & $1.84(0.27$ to 10.97$)$ \\
\hline $\begin{array}{l}\text { Methamphetamine } \\
>1 \mathrm{ng} / \mathrm{mL}\end{array}$ & $1.2(0.7$ to 2.0$)$ & 1.26 (0.35 to 5.63$)$ & 1.56 (0.40 to 5.46$)$ & 2.27 (0.65 to 8.23 ) & 5.04 (1.29 to 28.66$)$ & 0.58 (0.10 to 2.26 ) & 1.54 (0.39 to 5.38 \\
\hline $\begin{array}{l}\text { Methamphetamine } \\
>45 \mathrm{ng} / \mathrm{mL}^{*}\end{array}$ & $1.2(0.7$ to 2.0$)$ & 1.26( & 1.56 (0.40 to 5.46 ) & 2.27 (0.65 to & .29 to 28.66 ) & 0.58 & $1.54(0.39 t$ \\
\hline Any amphetamine $\dagger$ & 2.3 (1.5 to 3.3 ) & 1.79 (0.68 to 5.52$)$ & 2.34 (0.96 to 5.63 ) & 3.53 (1.45 to 9.15$)$ & $2.70(1.11$ to 7.00$)$ & 1.30 (0.52 to 3.12$)$ & 0.95 (0.33 to 2.42$)$ \\
\hline $\begin{array}{l}\text { Any amphetamine } \\
>\text { limit }\end{array}$ & 1.9 (1.3 to 2.9$)$ & 1.80 (0.63 to 6.35$)$ & 2.79 (1.06 to 7.41$)$ & 3.20 (1.22 to 9.00$)$ & $3.80(1.38$ to 12.07$)$ & 1.46 (0.54 to 3.82 ) & 0.76 (0.22 to 2.20$)$ \\
\hline Morphine > $1 \mathrm{ng} / \mathrm{mL} \ddagger$ & 2.3 (1.5 to 3.4 ) & $1.29(0.50$ to 3.74$)$ & 0.52 (0.13 to 1.58 ) & 2.23 (0.89 to 5.66 ) & 0.98 (0.37 to 2.45$)$ & 1.05 (0.38 to 2.66 ) & 3.40 (1.35 to 8.63$)$ \\
\hline Morphine $>24$ ng/mL* & $1.8(1.1$ to 2.8$)$ & $1.47(0.49$ to 5.30$)$ & 0.71 (0.17 to 2.28$)$ & 2.56 (0.90 to 7.53$)$ & 0.97 (0.32 to 2.76$)$ & 0.75 (0.21 to 2.26$)$ & 3.09 (1.07 to 8.89$)$ \\
\hline Any illicit drug§ & $10.0(8.4$ to 11.9$)$ & 1.55 (0.99 to 2.49$)$ & 1.41 (0.91 to 2.18$)$ & 2.90 (1.91 to 4.43 ) & 1.55 (1.03 to 2.35$)$ & 1.33 (0.86 to 2.02$)$ & 2.33 (1.53 to 3.54$)$ \\
\hline Any illicit drug >limit & 4.3 (3.2 to 5.7$)$ & $2.12(1.02$ to 4.84$)$ & 1.43 (0.73 to 2.72$)$ & 2.98 (1.58 to 5.74$)$ & 2.07 (1.10 to 3.95$)$ & 1.33 (0.69 to 2.50$)$ & 1.55 (0.80 to 2.94$)$ \\
\hline \multicolumn{8}{|c|}{ Medications $(>1 \mathrm{ng} / \mathrm{mL}) \S$ Age $<50(\mathrm{vs}>50) \S$} \\
\hline Diphenhydramineף & 4.7 (3.5 to 6.2$)$ & 2.02 & $1.76)$ & to 4.70$)$ & .44 to 1.65$)$ & $1.98)$ & $3.87(2.04$ to 7.46$)$ \\
\hline Benzodiazepines ${ }^{\star *}$ & 4.0 (2.9 to 5.3$)$ & 1.26 (0.63 to 2.68$)$ & 1.34 (0.66 to 2.92$)$ & 3.41 (1.74 to 6.91$)$ & 1.70 (0.87 to 3.33$)$ & 1.11 (0.54 to 2.19$)$ & 3.14 (1.61 to 6.17$)$ \\
\hline $\begin{array}{l}\text { Z-drugs (zopiclone, } \\
\text { zolpidem) }\end{array}$ & $0.6(0.3$ to 1.3$)$ & $0.74(0.12$ to 51.0$)$ & 0.71 (0.12 to 4.86$)$ & 2.58 (0.43 to 17.72$)$ & $1.11(0.16$ to 6.62$)$ & 0.32 (0.01 to 2.66$)$ & 3.29 (0.55 to 22.59$)$ \\
\hline Antidepressants & $6.5(5.2$ to 8.1$)$ & $0.52(0.31$ to 0.87$)$ & $0.59(0.35$ to 0.99$)$ & 1.84 (1.10 to 3.08$)$ & $0.80(0.46$ to 1.35$)$ & 0.80 (0.45 to 1.38$)$ & 1.45 (0.84 to 2.46$)$ \\
\hline Tricyclics† & $0.8(0.4$ to 1.6$)$ & 0.33 (0.05 to 1.72$)$ & $0.15(0.02$ to 0.79$)$ & 0.55 (0.06 to 2.90$)$ & $0.74(0.12$ to 3.49$)$ & 1.55 ( 0.31 to 7.26$)$ & $0.70(0.07$ to 3.69$)$ \\
\hline
\end{tabular}




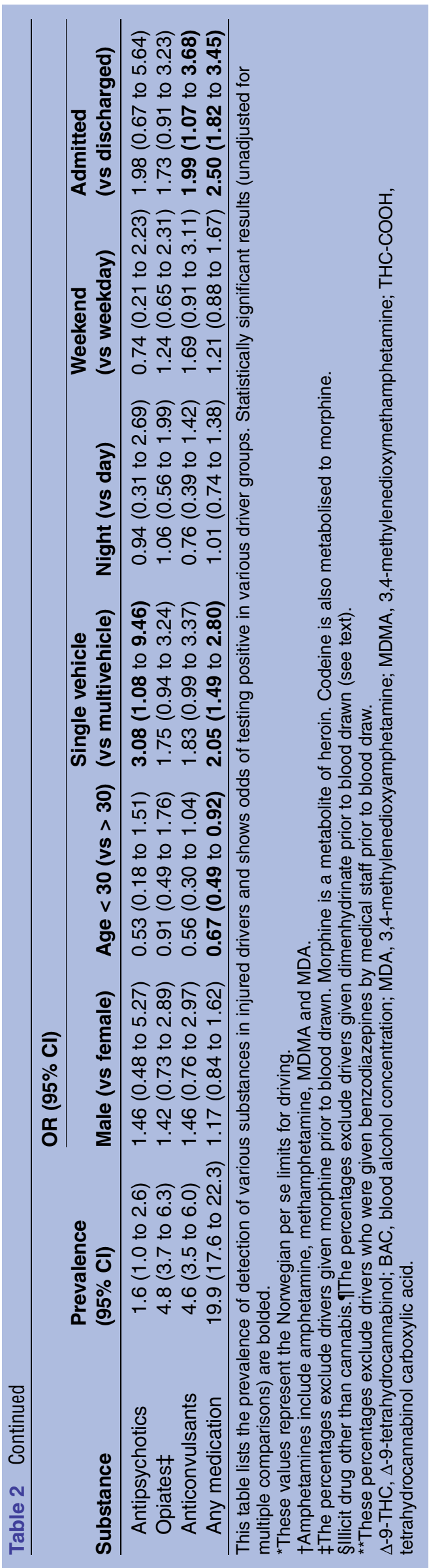

alcohol consumption and is highest in young drivers and at higher BAC levels. ${ }^{32} 33$ As expected, alcohol was more common in night-time drivers, in males, in drivers involved in single-vehicle crashes and in seriously injured drivers who required admission to hospital. The prevalence of alcohol use in this population of drivers, although high, is lower than typically seen in studies of injured drivers. For example, in previous research in $\mathrm{BC}$, we found that $47.1 \%$ of drivers captured in the BC trauma registry tested positive for alcohol. ${ }^{34}$ The lower prevalence in the current study likely reflects the fact that we are studying less severely injured patients (although all required bloodwork, only a third were admitted to hospital) and may also reflect a decrease in alcohol use by BC drivers following public campaigns against drunk driving and implementation of new traffic laws in BC (September 2010). These new laws targeted drinking drivers with immediate licence suspension and vehicle impoundment and resulted in marked reductions in alcohol-related fatal and injury crashes. ${ }^{35}$

After alcohol, cannabis was the next most commonly detected recreational drug. Like alcohol, cannabis impairs driving ability ${ }^{4}$ and increases the risk of crashes, although to a lesser extent than alcohol. ${ }^{14}{ }^{36-}$ ${ }^{38}$ We found evidence suggesting recent cannabis use (THC positive) in $7.3 \%$ of drivers. We also found that $3.0 \%$ of our drivers had $\triangle-9-$ THC levels above the Norwegian legal limit (THC=3 ng/mL) and $12.6 \%$ were cannabis users (ie, THC-COOH positive). $\Delta-9-\mathrm{THC}>3 \mathrm{ng} / \mathrm{mL}$ was more common in males and in drivers aged under 30 years but, unlike the case with alcohol, was not seen more commonly in drivers admitted to hospital, nor in those involved in night-time or single-vehicle crashes. It is possible that the numbers of drivers who use cannabis will increase with the recent boom in medical marijuana dispensaries of BC.

In addition to alcohol and cannabis, we found significant numbers of drivers who tested positive for illicit stimulants (cocaine, amphetamines). Stimulants actually improve some measures of driving ability such as reaction time, ${ }^{39} 40$ but in higher doses, stimulants impair judgment and are found to increase the risk of crashing in some studies. ${ }^{38}{ }^{41}$ We also found a high prevalence of the antihistamine, diphenhydramine. Diphenhydramine, often sold under the brand name Benadryl, is a common over-the-counter antihistamine that is used to treat allergic reactions, as a sleep aid (eg, Nytol), and as an ingredient of the antinausea medication Gravol (as dimenhydrinate). Antihistamines cause drowsiness and are known to impair driving performance. $^{42}$ Other sedating medications including opiates (morphine, codeine, methadone), benzodiazepines, Z-drugs (zopiclone) and antidepressants (tricyclic antidepressants, selective serotonin reuptake inhibitors, etc) were also common. Medications were most common in drivers aged over 50 years and in those requiring hospital admission. 
Figure 2 Polysubstance use. This Venn diagram shows the number and per cent of drivers testing positive for various combinations of substances. The font size for each drug combination is proportional to its prevalence.
Cannabis (7.3\%)

Other Recreational Drugs (10.0\%)

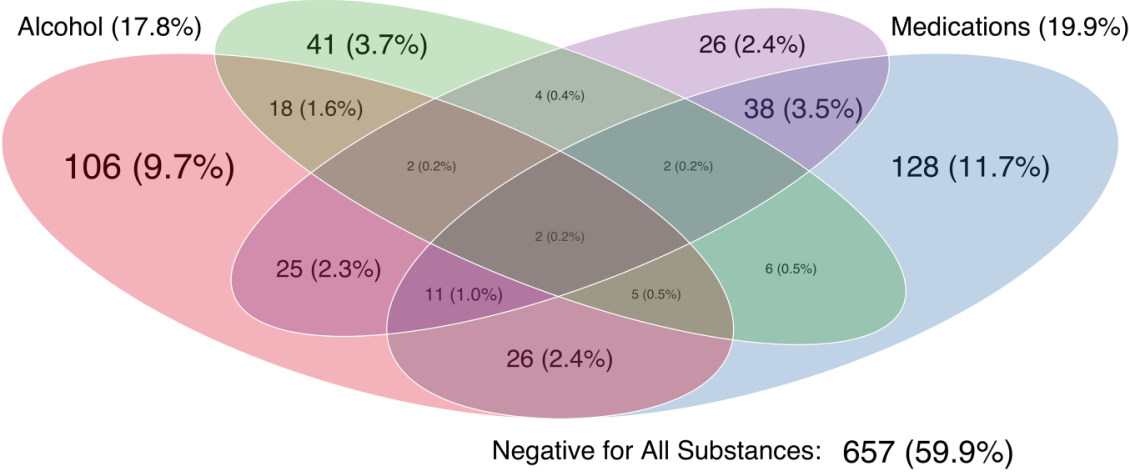

Other researchers have also investigated the prevalence of drug use in injured drivers. Our finding of positive $\mathrm{THC}-\mathrm{COOH}$ in $12.6 \%$ of drivers is slightly higher than that reported from Chicago in $1994(7.4 \%),{ }^{26}$ similar to Stoduto et al $\mathrm{s}^{24}$ study from Toronto $(13.9 \%)$, and far lower than the THC-COOH-positive rates reported from Colorado in 2001 (16.9\%), ${ }^{25}$ or Baltimore in $2005(26.9 \%) .{ }^{27}$ Only one other North American study was able to detect recent cannabis use (ie, $\Delta$-9-THC positive), but our finding that $7.3 \%$ of drivers test positive for $\Delta-9-\mathrm{THC}$ is similar to the results of recent studies from Australia, ${ }^{22} 43$ Belgium $^{44}$ and
France, ${ }^{45}$ lower than that seen in Spain, ${ }^{46}$ or Toronto-Halifax, ${ }^{28}$ and higher than that reported from Norway, ${ }^{47}$ Denmark ${ }^{19}$ or the Netherlands (2012). ${ }^{44}$

In $\mathrm{BC}$, the prevalence of drug and alcohol use in non-crash-involved drivers has also been studied in a series of roadside surveys which studied consenting drivers during weekend evenings and nights. In the most recent survey (2012), $6.5 \%$ of drivers had been drinking and $7.4 \%$ tested positive for another impairing drug, most commonly cannabis or cocaine. ${ }^{48}$ Although our crash-involved drivers cannot be directly compared with drivers from the roadside survey, the fact that we found
Figure 3 Prevalence of alcohol, cannabis and other drug use.

This figure shows the prevalence with $95 \%$ Cls of alcohol (top panel), cannabis (middle panel) and other drug use (bottom panel) in three groups of drivers: all drivers (black lines), alcohol-positive drivers (red lines) and $\Delta$-9-THC-positive drivers (green lines). As seen in this figure (top panel), cannabispositive drivers were more likely than other drivers to have also used alcohol. Similarly (middle panel), alcohol-positive drivers are more likely than other drivers to be cannabis users (detectable $\mathrm{THC}-\mathrm{COOH}$ ), or to have recently used cannabis (detectable $\Delta$-9-THC), but were not more likely to have $\Delta-9-\mathrm{THC}$ levels above the Norwegian limit of $3 \mathrm{ng} / \mathrm{mL}$ (middle panel). The lower panel shows that alcohol-positive drivers were more likely than other drivers to have also used a recreational drug other than cannabis. $\Delta-9-\mathrm{THC}$, $\Delta$-9-tetrahydrocannabinol; $\mathrm{THC}-\mathrm{COOH}$, tetrahydrocannabinol carboxylic acid.

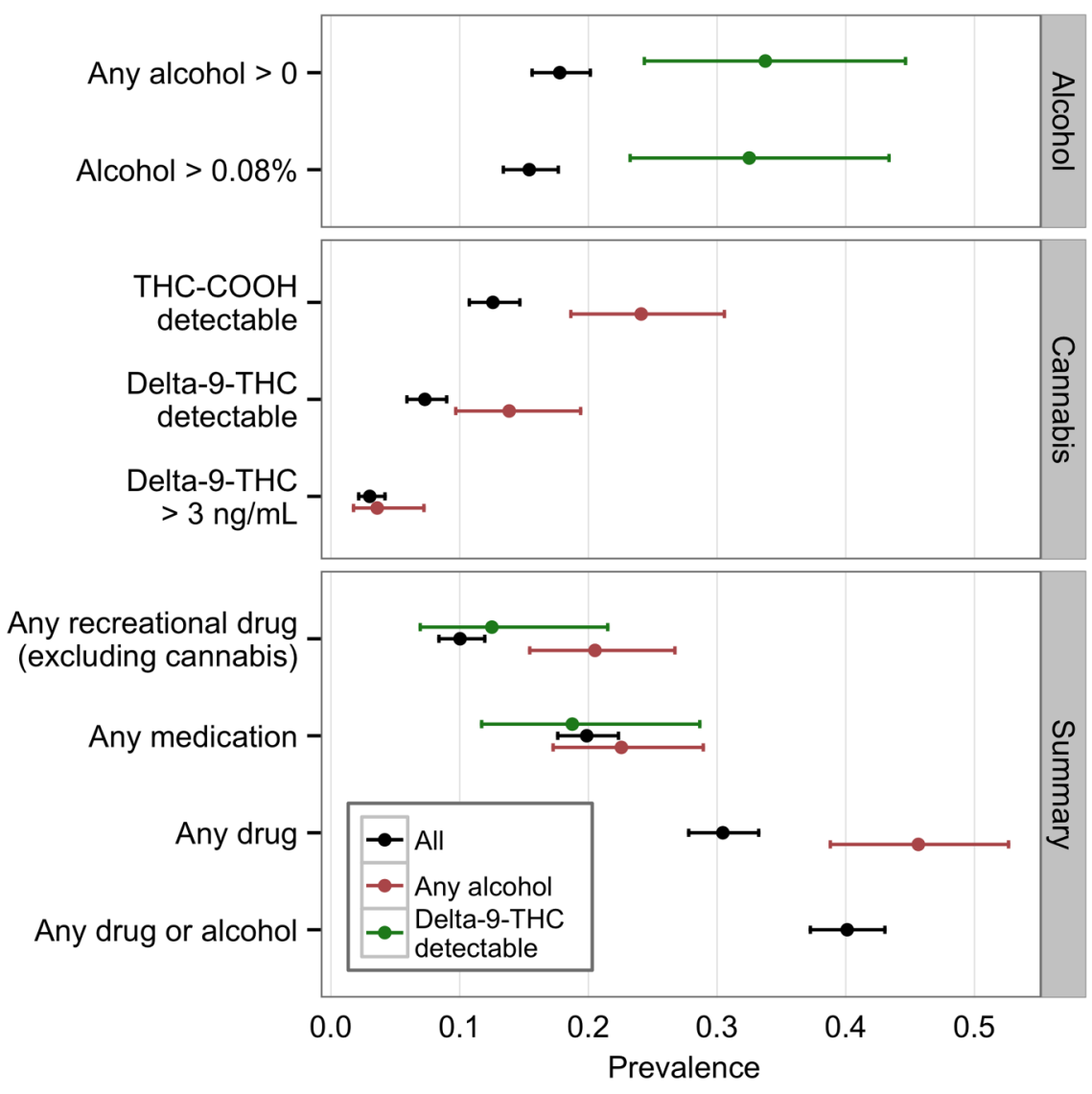


a much higher prevalence of drugs (other than cocaine) in crash-involved drivers supports the belief that drug use predisposes to crashes.

\section{Strengths}

Our study has several important strengths. Instead of using urine samples, we analysed blood samples to determine the prevalence of recent drug use in injured drivers. Most previous North American studies were unable to distinguish between drivers with positive metabolites and those with active drug in their blood. An additional strength is that, rather than reporting the results of drug screening performed for clinical purposes (ie, based on clinical suspicion of drug use), we analysed excess blood that had been obtained for other clinical purposes (ie, not for drug screening) and that remained after clinical use. In this way, we studied a more representative sample of injured drivers who required bloodwork as part of their clinical care and avoided the risk of selecting only drivers who were suspected of using drugs. In addition, this study had research ethics board approval for waiver of consent because we used excess blood that had been obtained for clinical use and was going to be discarded, and because of the procedures we put in place making it impossible to link toxicology results back to an individual driver. The advantage of this is that we avoid the selection bias that could occur if consent was required and drivers who used drugs were more likely to refuse to participate.

\section{Limitations}

Our study also has several weaknesses that result from our reliance on excess blood. First, the excess blood volumes are small which limits analysis in some cases. In particular, we did not always have sufficient blood to perform quantification of drugs (other than cannabinoids). However, the analytic process is sufficient for the purpose of detecting presence versus absence of all drugs. Second, we obtained blood from only those drivers who had serious enough injuries that they required blood analysis as part of routine care. This means that drivers with minor injuries were not included and our findings do not apply to drivers with less severe injuries.

\section{CONCLUSIONS}

Alcohol, cannabis and other impairing drugs were commonly detected in injured BC drivers. Alcohol and cannabis were both found more commonly in males and in drivers aged under 30 years. Many drivers used alcohol and cannabis together, resulting in increased impairment. Legal impairing medications were also commonly detected. Medications are used more often in drivers aged over 50 years and in drivers who require admission to hospital after a crash.

Alcohol and, to a lesser extent, cannabis are known to cause crashes. Our findings suggest that alcohol continues to be the most important cause of impaired driving, followed by cannabis. The number of drivers using cannabis may increase with the growing numbers of medical marijuana dispensaries in BC and with legalisation of marijuana in some US states. Impairing medications are also a significant concern and, as the population ages, the prevalence of medication use by drivers is likely to increase even higher. The crash risk associated with most impairing medications is poorly studied and more work in this field is required to inform educational programmes designed to prevent medication-involved crashes. In addition, many drivers use several drugs in combination and more research is required to understand the risk of impairment associated with polysubstance use.

As the population ages, the prevalence of medication use by drivers will likely increase. More work is needed to understand the role of medications in causing crashes to guide driver education programmes and improve public safety.

\section{Author affiliations}

${ }^{1}$ Department of Emergency Medicine, University of British Columbia,

Vancouver, British Columbia, Canada

${ }^{2}$ Provincial Toxicology Centre, Vancouver, British Columbia, Canada

${ }^{3}$ Department of Pathology and Laboratory Medicine, The University of British Columbia, Vancouver, British Columbia, Canada

${ }^{4}$ Department of Community Health and Epidemiology, Dalhousie University, Halifax, Nova Scotia, Canada

${ }^{5}$ University of Victoria, Centre for Addiction Research of British Columbia, Vancouver, British Columbia, Canada

${ }^{6}$ Department of Forensic Medicine, Monash University, Melbourne, Victoria, Australia

${ }^{7}$ Provincial Health Services Authority, British Columbia Centre for Disease Control, Vancouver, British Columbia, Canada

${ }^{7}$ Faculty of Medicine, University of Toronto, Toronto, Ontario, Canada

${ }^{8}$ Department of Statistics, University of British Columbia, Vancouver, British

Columbia, Canada

Acknowledgements The authors thank Stirling Bryan, PhD, and Henk Van Zyl, MD, for their input and support.

Contributors This study was designed by JRB and $\mathrm{HC}$ with input from all the authors. $\mathrm{HC}$ managed study logistics as a whole. WM and WS oversaw toxicological analysis with input from OD. GA, JE and AL helped with study logistics. RB provided help with statistical analysis. MA, OD, RM, SM and RP provided content expertise. All authors were involved with manuscript writing.

Funding This study was funded by the Canadian Institutes of Health Research. Dr Brubacher's research is supported by a scholar award from the Michael Smith Foundation for Health Research.

Competing interests None declared.

Ethics approval The University of British Columbia Clinical Research Ethics Board.

Provenance and peer review Not commissioned; externally peer reviewed.

Data sharing statement No additional data are available.

Open Access This is an Open Access article distributed in accordance with the Creative Commons Attribution Non Commercial (CC BY-NC 4.0) license, which permits others to distribute, remix, adapt, build upon this work noncommercially, and license their derivative works on different terms, provided the original work is properly cited and the use is non-commercial. See: http:// creativecommons.org/licenses/by-nc/4.0/ 


\section{REFERENCES}

1. Leufkens TR, Vermeeren A, Smink BE, et al. Cognitive, psychomotor and actual driving performance in healthy volunteers after immediate and extended release formulations of alprazolam $1 \mathrm{mg}$. Psychopharmacology (Berl) 2007;191:951-9.

2. Ramaekers JG, Kauert G, van Ruitenbeek P, et al. High-potency marijuana impairs executive function and inhibitory motor control. Neuropsychopharmacology 2006;31:2296-303.

3. Wingen M, Ramaekers JG, Schmitt JA, et al. Driving impairment in depressed patients receiving long-term antidepressant treatment. Psychopharmacology (Berl) 2006;188:84-91.

4. Ramaekers JG, Berghaus G, van Laar M, et al. Dose related risk of motor vehicle crashes after cannabis use. Drug Alcohol Depend 2004;73:109-19.

5. Ramaekers JG. Antidepressants and driver impairment: empirical evidence from a standard on-the-road test. $J$ Clin Psychiatry 2003;64:20-9.

6. Orriols L, Salmi LR, Philip P, et al. The impact of medicinal drugs on traffic safety: a systematic review of epidemiological studies. Pharmacoepidemiol Drug Saf 2009;18:647-58.

7. Dassanayake T, Michie P, Carter G, et al. Effects of benzodiazepines, antidepressants and opioids on driving: a systematic review and meta-analysis of epidemiological and experimental evidence. Drug Saf 2011;34:125-56.

8. Orriols L, Philip P, Moore N, et al. Benzodiazepine-like hypnotics and the associated risk of road traffic accidents. Clin Pharmacol Ther 2011;89:595-601.

9. Smink BE, Egberts ACG, Lusthof KJ, et al. The relationship between benzodiazepine use and traffic accidents: a systematic literature review. CNS Drugs 2010;24:639-53.

10. Rapoport MJ, Lanctot KL, Streiner DL, et al. Benzodiazepine use and driving: a meta-analysis. J Clin Psychiatry 2009;70: 663-73.

11. Ravera S, Ramaekers JG, de Jong-van den Berg LTW, et al. Are selective serotonin reuptake inhibitors safe for drivers? What is the evidence? Clin Ther 2012;34:1070-83.

12. Vindenes V, Lund HM, Andresen W, et al. Detection of drugs of abuse in simultaneously collected oral fluid, urine and blood from Norwegian drug drivers. Forensic Sci Int 2012;219: 165-71.

13. Grotenhermen F, Leson G, Berghaus G, et al. Developing limits for driving under cannabis. Addiction 2007;102:1910-7.

14. Hartman RL, Huestis MA. Cannabis effects on driving skills. Clin Chem 2013:59:478-92.

15. Huestis MA, Henningfield JE, Cone EJ. Blood cannabinoids. I. Absorption of THC and formation of 11-OH-THC and $\mathrm{THCCOOH}$ during and after smoking marijuana. J Anal Toxicol 1992;16:276-82.

16. Huestis MA, Barnes A, Smith ML. Estimating the time of last cannabis use from plasma delta9-tetrahydrocannabinol and 11-nor-9-carboxy-delta9-tetrahydrocannabinol concentrations. Clin Chem 2005;51:2289-95.

17. Vindenes V, Jordbru D, Knapskog AB, et al. Impairment based legislative limits for driving under the influence of non-alcohol drugs in Norway. Forensic Sci Int 2012;219:1-11.

18. Beirness DJ, Beasley EE. Alcohol and Drug Use Among Drivers: British Columbia Roadside Survey 2008. Ottawa, ON: Canadian Centre on Substance Abuse, 2009. http://www.ccsa.ca/2009\% 20CCSA\%20Documents/ccsa0115382009_e.pdf

19. Wiese Simonsen K, Steentoft A, Bernhoft IM, et al. Psychoactive substances in seriously injured drivers in Denmark. Forensic Sci Int 2013;224:44-50.

20. Gjerde H, Christophersen AS, Normann PT, et al. Norwegian roadside survey of alcohol and drug use by drivers (2008-2009). Traffic Inj Prev 2013;14:443-52.

21. Bernhoft IM, Schulze H. Results from epidemiological researchPrevalence, risk and characteristics of impaired drivers. Bergisch-Gladbach, Germany: Federeal Highway Research Institute, 2011.

22. Drummer $\mathrm{OH}$, Kourtis I, Beyer J, et al. The prevalence of drugs in injured drivers. Forensic Sci Int 2012;215:14-7.

23. Wong OF, Tsui KL, Lam TSK, et al. Prevalence of drugged drivers among non-fatal driver casualties presenting to a trauma centre in Hong Kong. Hong Kong Med J 2010;16:246-51.

24. Stoduto G, Vingilis E, Kapur BM, et al. Alcohol and drug use among motor vehicle collision victims admitted to a regional trauma unit: demographic, injury, and crash characteristics. Accid Anal Prev 1993;25:411-20.
25. Lowenstein SR, Koziol-McLain J. Drugs and traffic crash responsibility: a study of injured motorists in Colorado. J Trauma 2001;50:313-20.

26. Orsay EM, Doan-Wiggins L, Lewis $R$, et al. The impaired driver: hospital and police detection of alcohol and other drugs of abuse in motor vehicle crashes. Ann Emerg Med 1994;24:51-5.

27. Walsh JM, Flegel R, Atkins R, et al. Drug and alcohol use among drivers admitted to a Level-1 trauma center. Accid Anal Prev 2005;37:894-901.

28. Asbridge M, Mann R, Cusimano MD, et al. Cannabis and traffic collision risk: findings from a case-crossover study of injured drivers presenting to emergency departments. Int $J$ Public Health 2014:59:395-404.

29. Giroud C, Menetrey A, Augsburger M, et al. Delta(9)-THC, 11-OH-Delta(9)-THC and Delta(9)-THCCOOH plasma or serum to whole blood concentrations distribution ratios in blood samples taken from living and dead people. Forensic Sci Int 2001;123:159-64.

30. Couper FJ, Logan BK. Drugs and human performance fact sheets. Washington DC: National Highway Traffic Safety Administration. 2014. http://www.nhtsa.gov/staticfiles/nti/pdf/ 809725-DrugsHumanPerformFS.pdf

31. Borkenstein RF, Crowther RF, Shumate RP, et al. The role of the drinking driver in traffic accidents (the Grand Rapids Study). Blutalcohol 1974;11(Suppl):7-13.

32. Blomberg RD, Peck RC, Moskowitz H, et al. The Long Beach/Fort Lauderdale relative risk study. J Safety Res 2009;40:285-92.

33. Peck RC, Gebers MA, Voas RB, et al. The relationship between blood alcohol concentration (BAC), age, and crash risk. J Safety Res 2008;39:311-9.

34. Purssell RA, Yarema M, Wilson J, et al. Proportion of injured alcohol impaired drivers convicted of a criminal code offence in British Columbia. Can J Emerg Med 2004;6:80-8.

35. Brubacher JR, Chan $\mathrm{H}$, Brasher $\mathrm{P}$, et al. Reduction in fatalities, ambulance calls, and hospital admissions for road trauma after implementation of new traffic laws. Am J Public Health 2014;104 e89-97.

36. Asbridge M, Hayden JA, Cartwright JL. Acute cannabis consumption and motor vehicle collision risk: systematic review of observational studies and meta-analysis. BMJ 2012;344:e536.

37. Li MC, Brady JE, DiMaggio CJ, et al. Marijuana use and motor vehicle crashes. Epidemiol Rev 2012;34:65-72.

38. Elvik R. Risk of road accident associated with the use of drugs: a systematic review and meta-analysis of evidence from epidemiological studies. Accid Anal Prev 2013;60:254-67.

39. Ramaekers JG, Kuypers KPC, Bosker WM, et al. Effects of stimulant drugs on actual and simulated driving: perspectives from four experimental studies conducted as part of the DRUID research consortium. Psychopharmacology (Berl) 2012;222:413-8.

40. Hjalmdahl M, Vadeby A, Forsman A, et al. Effects of d-amphetamine on simulated driving performance before and after sleep deprivation. Psychopharmacology (Berl) 2012;222:401-11.

41. Laumon B, Gadegbeku B, Martin JL, et al. Cannabis intoxication and fatal road crashes in France: population based case-control study. BMJ 2005;331:1371.

42. Hindmarch I, Shamsi Z. Antihistamines: models to assess sedative properties, assessment of sedation, safety and other side-effects. Clin Exp Allergy 1999;29(Suppl 3):133-42.

43. Ch'ng CW, Fitzgerald M, Gerostamoulos J, et al. Drug use in motor vehicle drivers presenting to an Australian, adult major trauma centre. Emerg Med Australas 2007;19:359-65.

44. Legrand SA, Houwing S, Hagenzieker M, et al. Prevalence of alcohol and other psychoactive substances in injured drivers: comparison between Belgium and The Netherlands. Forensic Sci Int 2012;220:224-31.

45. Mura P, Kintz P, Ludes B, et al. Comparison of the prevalence of alcohol, cannabis and other drugs between 900 injured drivers and 900 control subjects: results of a French collaborative study. Forensic Sci Int 2003;133:79-85.

46. Santamarina-Rubio E, Perez K, Ricart I, et al. Substance use among road traffic casualties admitted to emergency departments. Inj Prev 2009;15:87-94.

47. Bogstrand ST, Gjerde H, Normann PT, et al. Alcohol, psychoactive substances and non-fatal road traffic accidents-a case-control study. BMC Public Health 2012;12:734.

48. Beasley EE, Beirness DJ. Alcohol and Drug Use Among Drivers Following the Introduction of Immediate Roadside Prohibitions in British Columbia: Findings from the 2012 Roadside Survey2012. http://www.pssg.gov.bc.ca/osmv/data/index.htm 